\title{
DOCUMENTATION \& CONDITION MAPPING FOR RESTORATION \& REVITALISATION OF HISTORIC SHEESH MAHAL \& CHAR BAGH COMPLEX IN PATIALA (PUNJAB), INDIA
}

\author{
Shalini Dasgupta \\ Principal Conservation Architect - Heritage Conservation \& Design Centre, New Delhi, India, hcdcdesigns@gmail.com \\ Visiting Faculty - School of Planning \& Architecture; Dept. of Architectural Conservation
}

KEY WORDS: Documentation, Heritage Inventories, Condition Mapping, Heritage Management, Conservation, Revitalisation

\begin{abstract}
:
Located in the Northern State of Punjab, the historic city of Patiala has always been a centre of culture in north India, and has seen the evolution of its own distinct style of architecture with Rajput and Mughal influences. The city is renowned for its rich architectural heritage, Music, Craft, Sports and Cuisine. The fourth Maharaja Narinder Singh was a great patron of art, architecture and music and it was during his time that several palaces like the Moti Bagh Palace, Sheesh Mahal and Banasur Bagh were designed followed by Baradari Palace. Later it was Maharaja Bhupinder Singh (1900-1938) who made Patiala State famous with his lavish lifestyle.This paper describes the process followed for Documentation and condition assessment of the historic Sheesh Mahal \& Char Bagh Complex in order to restore and revitalise the palace building and the Mughal garden. The exercise included Archival research, Field surveys, Condition Mapping, inventories using traditional methods as well as GIS and preparation of restoration \& conservation solutions along with post conservation management manual. The Major challenges encountered were identifying the correct documentation methodology for mapping as well as managing the large database generated on site. The Documentation and Mapping was used as a significant tool to guide towards the conservation and Management strategy of the complex.
\end{abstract}

\section{INTRODUCTION}

\subsection{Context}

The city of Patiala was founded in 1764 by Baba Ala Singh on an ancient mound, "Prasthala", referred to in the Mahabharata. A man of vision and courage, Ala Singh carved out an independent principality from a petty Zamindari of 30 villages and under his successors, it expanded into a big State, touching the Shivaliks in north, Rajasthan in the south and upper courses of the Jamuna and the Sutlej. After the third Battle of Panipat in 1761 in which the Marathas were defeated, the writ of the Afghans prevailed throughout Punjab and the rulers of Patiala acquired ensigns of royalty from Ahmad Shah Abdali. He bestowed upon Ala Singh, the drum and banner, and his grandson Amar Singh received the title of Raja-i-Rajgan and had his own mint. Baba Ala Singh laid the foundation of the fort known as Quila Mubarak, around which the present city of Patiala is built, which was the capital of the princely state of Patiala.

Patiala has always been a centre of culture in north India, and has seen the evolution of its own distinct style of architecture with Rajput and Mughal influences. With royal patronage, a well established style of Hindustani music called 'the Patiala Gharana' came into existence, many of whose proponents came to Patiala after the disintegration of the Mughal Court at Delhi in the 18th century. The fourth Maharaja Narinder Singh was a great patron of art, architecture and music and it was during his time that several palaces like the Moti Bagh Palace, Sheesh Mahal and Banasur Bagh were designed followed by Baradari Palace. Later it was Maharaja Bhupinder Singh (1900-1938) who made Patiala State famous with his lavish lifestyle. Patialvi crafts have always been famous especially the traditional "Phulkari" embroidery, colourful Parandas (hair ornaments), Nalas (decorative cords), Dupattas and Juttis (shoes) embroidered in elaborate motifs with gold thread. The city has a rich tradition of sports dating back to Baba Ala Singh who encouraged horsemanship, marksmanship and hunting. Later Cricket was introduced and Patiala state had the highest cricket ground in the world at Chail (now in Himachal Pradesh). During colonial times, the Patiala Polo and Hockey teams were internationally famous. Patiala is now a national centre of sports with the establishment of the National Institute of Sports in the Sheesh Mahal complex.

\subsection{Sheesh Mahal and Char Bagh}

Maharaja Narendra Singh was a great patron of literature, music and fine arts. He invited many painters from Kangra and Rajasthan to paint the walls of Sheesh Mahal. Their works depict the poetry of Keshav, Surdas and Bihari and the themes of these paintings embrace mythology, legends, Raga-Ragni, Nayak-Nayika and Bara-masa in Rajasthani style. The walls and ceilings are embellished in floral motifs. The museum has a rich collection of miniature paintings of the 19th century based on the Geet Gobinda and Jayadev's poetry. The Kangra paintings depict the Krishan Lila and the Rag-mala paintings of the Rajasthan and Mughal schools give visual meaning to the Ragas of Hindustani classical music.

There are also fine objects of Tibetan art especially different types of metal sculpture. Ivory carvings of Punjab, royal wooden carved furniture, and a large number of Burmese and Kashmiri carved objects are also exhibited. One can see the huge portraits of the rulers of Patiala adorning the walls of museum hall. There are rare Janamsakhi and Jain manuscripts and the most valuable poems, Gulistan and Bustan by the famous Sufi, Sheikh Sadi of Shiraz, acquired by the Emperor Shah Jahan for his personal library. 


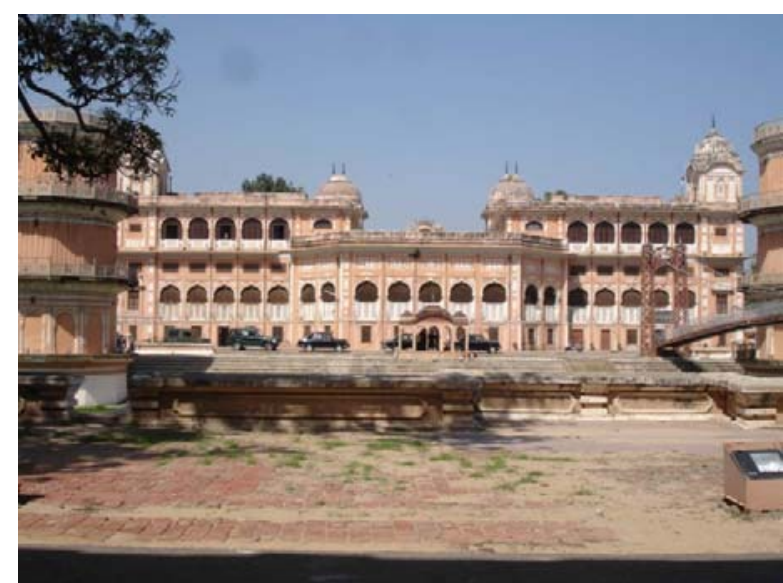

Figure 1: The Sheesh Mahal Exterior Front Facade

The Medal Gallery here has 3200 medals and decorations, the largest collection in the world. Collected by Maharaja Bhupinder Sing, his son Maharaja Yadavindra Singh gifted the entire priceless collection to the Museum. The most valuable are The Order of the Garter (England) of 1348 A.D., The Order of the Golden Fleece (Austria) founded in

1430 A.D. The Order of St. Andrews (Russia) founded in 1688 by Peter the Great; The Order of the Rising Sun (Japan), Order of the Double Dragon (China) and The Order of the White Elephant (Thailand). The collection contains medals from Belgium, Denmark, Finland and host of other countries of Africa and Asia. Maharaja Ranjit Singh and Maharaja Dalip Singh also issued medals which are studded with precious stones. Some of them display miniature paintings of the Maharaja in profile in the centre. Also displayed is a rare collection of coins from punch-marked coins to those issued by the princely states in the 19th Century.

\subsection{Project \& Objectives}

The Aim of the project was Revitalization of Sheesh mahal \& Char Bagh Complex, through conservation of its natural and cultural resources and, further develop the site in a manner which is appropriate to its cultural significance, thus promoting an 'enhanced visitor experience'.

\section{The Startegy:}

- Minimal Intervention Approach

- The Sheesh Mahal is clearly a very important and significant site for the city of Patiala. There is a need to conserve the spirit of the Mughal \& English landscape within which the complex is set, respecting and enhancing the sanctity and historic value of the structures within it.

This site is visualised in three parts - The Front Entrance Space, The Central open water tank with the main building elements of the complex thrown around it and the rear or originally the front mughal char bagh garden against which the sheesh mahal complex was set.

\section{Site Significance:}

Sheesh Mahal \& Char Bagh complex is of historical significance as it is one of the few surviving chahar bagh gardens in the region as a record of garden design activity in the late nineteenth century under Maharaja Narinder Singh (18451862). It has an identity as an indigenous adaptation of the Mughal chahar bagh style qualifying it as an important example of the Sikh provincial garden style of the late nineteenth century.

The Complex is of immense cultural significance because of its association with Maharaja Narinder Singh (1845-1862) who laid out the gardens as part of his summer residence. As a summer palace of the time (late nineteenth century) it is a reflection of the royal living style of the period.

The gardens of Sheesh Mahal which also include the Banasar tank landscape are of cultural significance because they are unique in their existence as twin gardens, one reflecting the English / Colonial landscape style and the other the Mughal chahar bagh style.

The Complex / garden is of ecological significance as it exhibits an unusually large collection of fruit trees in the chahar bagh area.

The Sheesh Mahal and Char Bagh Complex is a very important and significant heritage site. There was a need to conserve both the Palace and the gardens, both in spirit and in content as examples of the English Landscape style and the Mughal chahar bagh style along with Rajput Architectural style. All the values mentioned above were under threat and the complex was in urgent need of conservation.

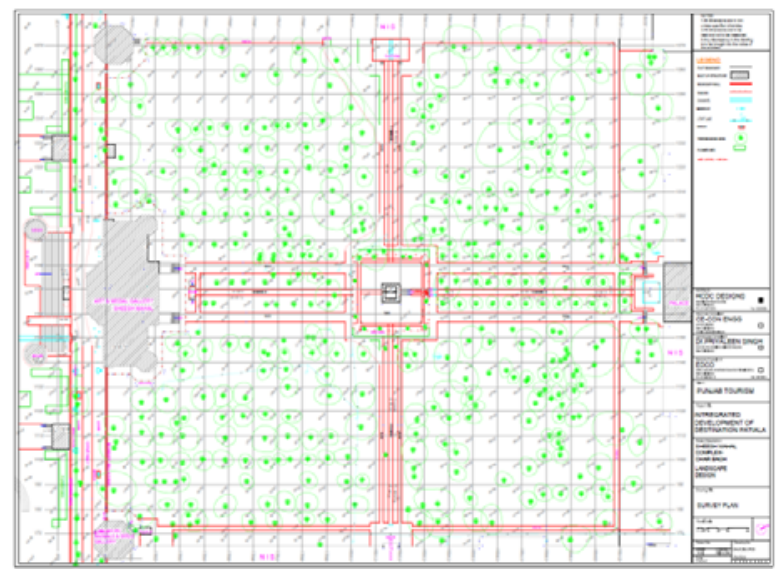

Figure 2: Site survey plan of the complex

The objective of documenting the Sheesh Mahal Palace structure and the Char Bagh Garden was to produce an accurate record of the building and the landscape with condition mapping of the exterior and interior surfaces.

As mentioned by Letellier and LeBlanc (2007), "Heritage Recording is the capturing of graphic and photographic information describing the physical configuration, evolution, and condition of the heritage place...the resulting heritage record is a technical dossier consisting of graphic records that provide the necessary basic data for conservation and conservation related activities" [1].

Based on this, the team identified a suitable surveying and documenting technique which was then used for condition mapping and to further design the strategy for their conservation.

The recording was primarily conducted with close -range photogrammetry techniques and other prevalent image processing technologies. Proximity to sites, portability of equipments, Cost effectiveness and non - invasive nature of techniques were major considerations for technique selection. 


\section{THE DOCUMENTATION PROCESS}

\subsection{Selection of documentation techniques \& recording}

The Palace and the garden complex had a diverse range of products to be documented. The decorative exterior of the palace, the ornate interior of the palace, the ornate painted chambers within the palace, the garden (Mughal char bagh) with its landscaping components like the fountain channels, fountains, water cascades, etc.

The first part of the documentation was undertaken as taking photographs using a high resolution DSLR camera. For even lighting flash equipped with diffusers was used. A series of overlapping images and panoramas were recorded to make sure all surfaces were photo documented. Due to time and financial constraint, to produce measured drawings it was decided that photogrammetry would be the most efficient method.
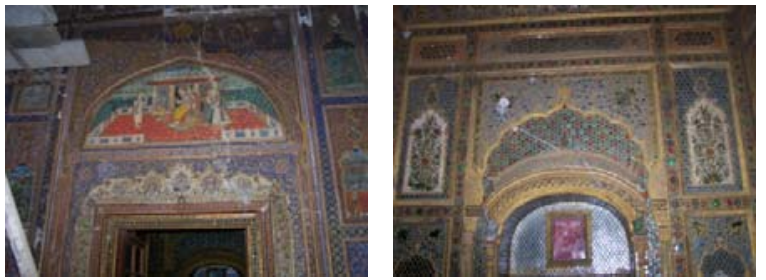

Figure 3: The painted chambers of Sheesh Mahal

Photogrammetry, as its name implies, is a 3-dimensional coordinate measuring technique that uses photographs as the fundamental medium for metrology (or measurement). The fundamental principle used by Photogrammetry is triangulation or more specifically called Aerial Triangulation. By taking photographs from at least two different locations, so-called "lines of sight" can be developed from each camera to points on the object. These lines of sight (sometimes called rays owing to their optical nature) are mathematically intersected to produce the 3-dimensional coordinates of the points of interest.

The second part of documenting was the detail architectural documentation of plans, sections and elevations of the palace and the garden. The survey team used an Electronic Distance Measurement (EDM) along with the Total Stations connected to PCs equipped with AutoCAD software. The measurements collected by the EDMs were translated to AutoCAD. The Total Stations were used to survey the exterior, marking the extent of the char bagh and the location of components within.

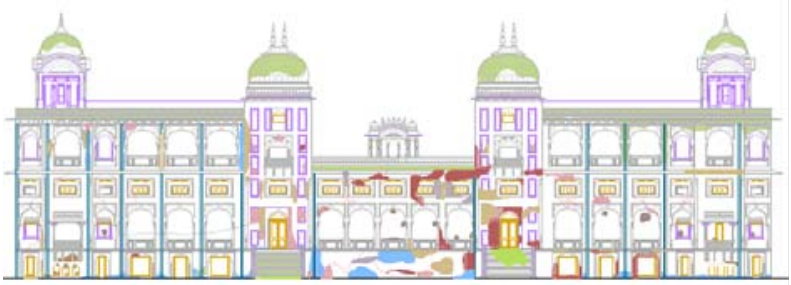

Figure 4: Rear Elevation of Sheesh Mahal
Additional Photogrammetry was undertaken to ensure all small chambers and all surfaces were thoroughly covered. This was used to generate Vertical and horizontal profiles which then helped in converting the data into plans, sections and elevations.

\subsection{Assimilation of CAD Drawings}

The final set of drawings is a amalgamation of all data collected through photography, total station survey, photogrammetry and hand measurements. These final set of drawings are reproduced through CAD software with appropriate scale and measurements.

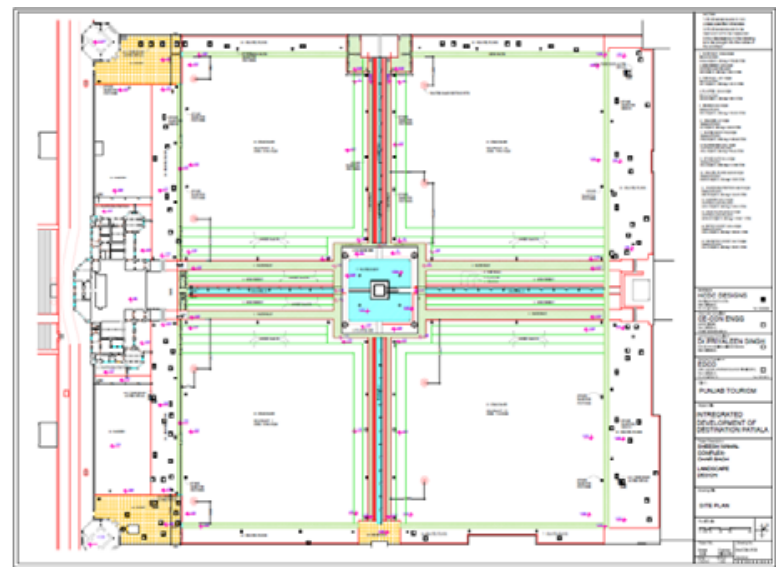

Figure 5: The Mughal Char Bagh

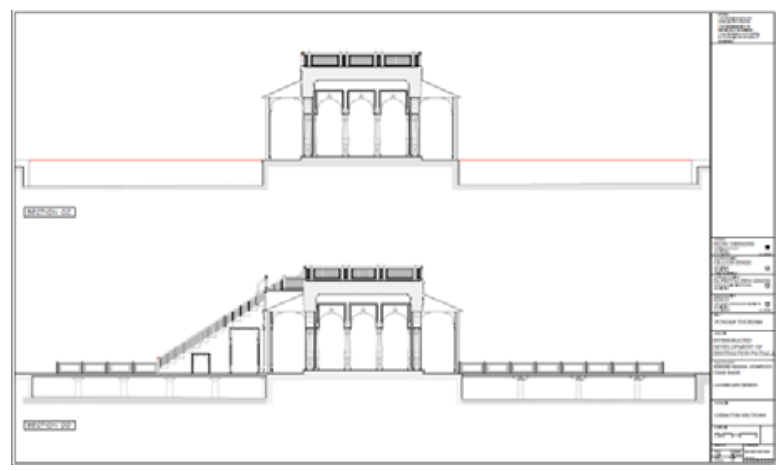

Figure 6: Section through the fountain

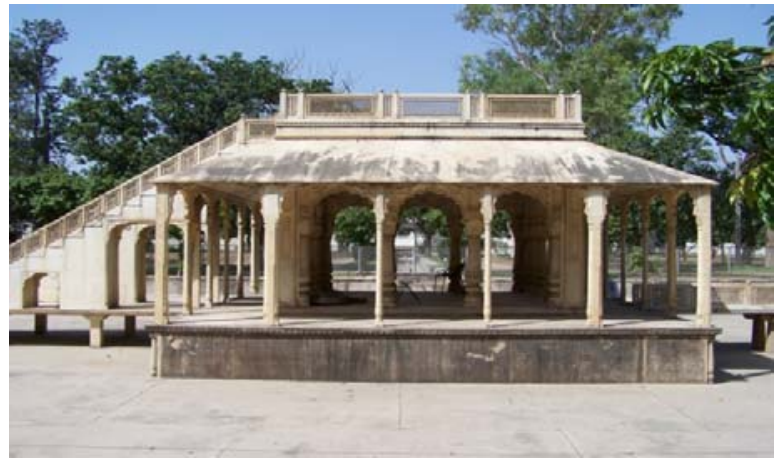

Figure 7: The central fountain Pavillion 


\section{3 : Condition Mapping}

The condition Mapping was the next level of documentation. Each and every chamber and all surfaces were examined with non - invasive methods to record the condition. Along with Visual inspections wherever required floors and ceilings had to be opened and investigated with extreme care. Condition Mapping was conducted at different level from exterior elevations to interior surfaces to museum artifacts.

The base measured drawings were used to map and inventory the list of defects and deteriorations identified on inspection. These in turn helped assess the condition and inform the decision on the proposed remedies and repair of the defects.
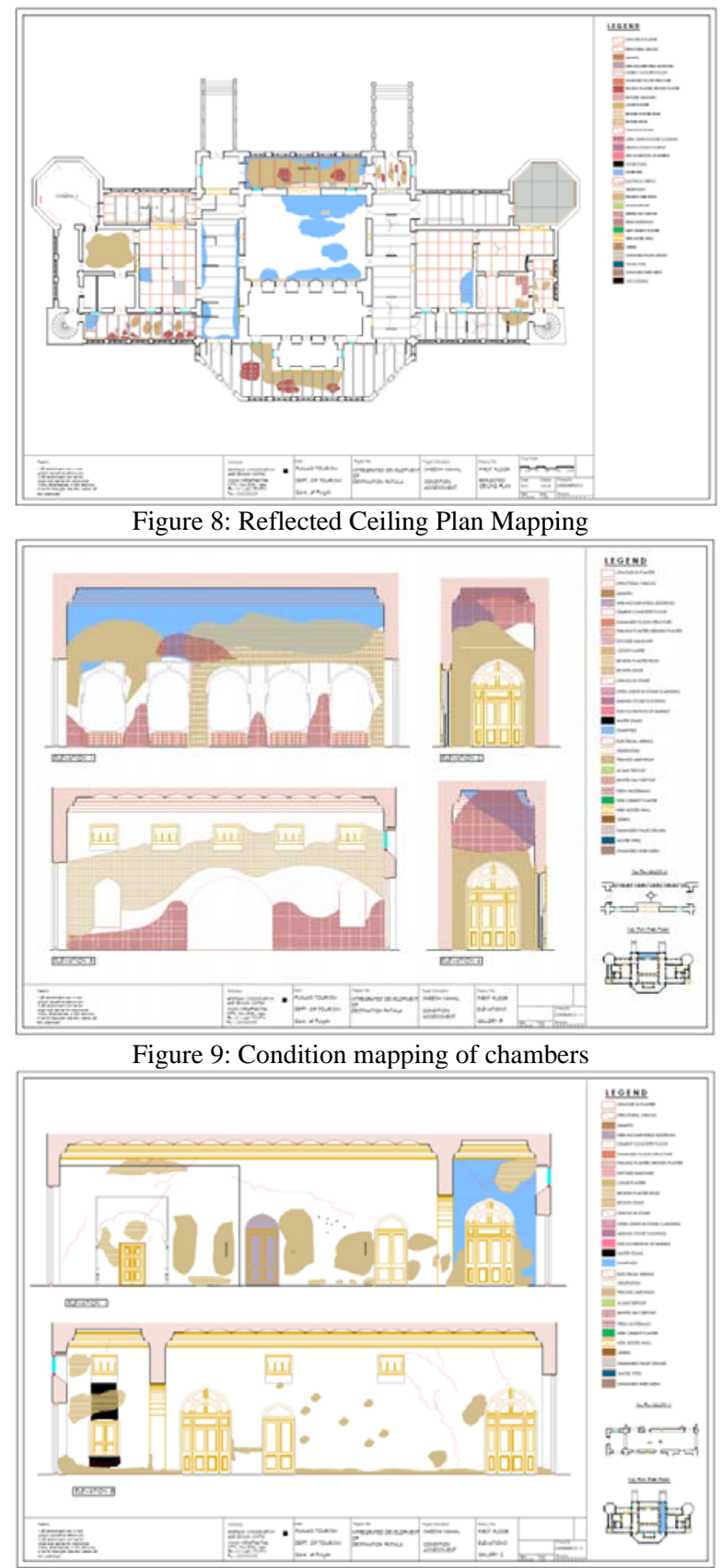

Figure 10: Condition mapping of chambers

\section{CONSERVATION PLANNING}

3.1 The measured drawings generated were used to assess the deterioration and structural damage. It also helped in identifying the character defining features of the site to be protected and the documented for posterity. The measure drawings were also used to propose the restoration plan and help the contractor implement the work through the same drawings.

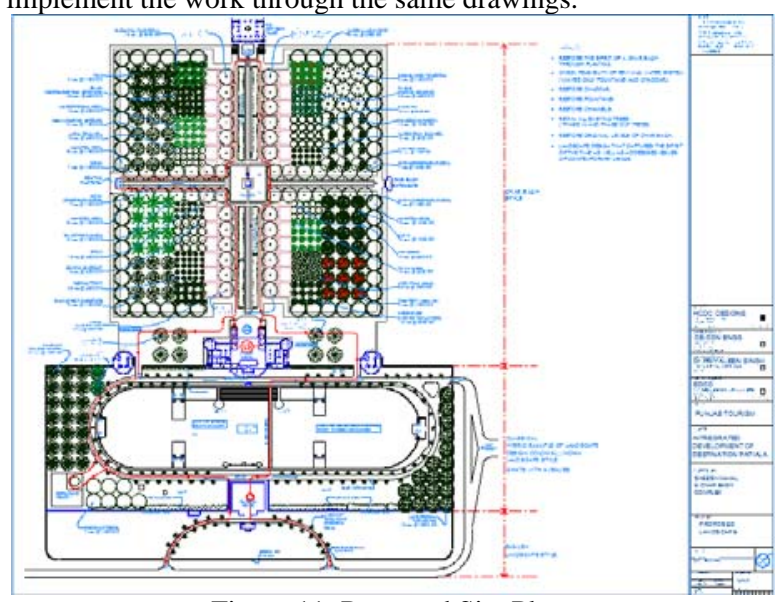

Figure 11: Proposed Site Plan

The site is divided into three segments -

The Front Entrance Space - the front entrance court as the visitor receiving area along with the entrance gateways and Banassar Ghar. It is proposed to include this area in the redevelopment works as this space acts as the interface with the city. It is the starting point of the visitor experience. It is here that a visitor whether passing by or stopping gathers his/her first impressions of the site.

The Central Space with the water tank and the main building components - This space is seen as the setting to the Sheesh Mahal complex with all building components placed around the huge central water tank. Removal of all new additions with minimal design interventions in this space to create a foreground to the majestic environment of the complex is proposed.

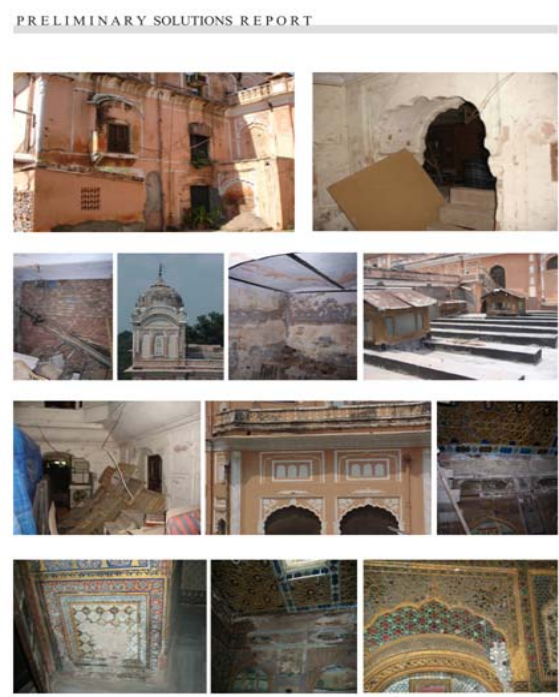

IMAGE BOARD SHOWING DETERIORATED CONDTION OF THE SHEESH MAHAL INTERIORS

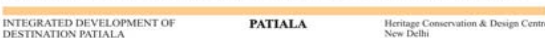


The Innermost 'Char Bagh' garden - The 'Char Bagh' between the new and the old Moti Bagh Palace is seen as an experiential and educational zone for the visitor. The design is planned to make the visitor experience the spirit of the historic 'char bagh' garden as it would have been historically.

Conservation works of the Main Sheesh Mahal Palace Building, which was in urgent need of repair.

- $\quad$ Structural consolidation of the structure.

- All vegetation removal from the structure.

- Dismantling new additions, cement plaster and deteriorated lime plaster from the walls.

- Removal of lime wash and algae from wall surfaces and ceiling.

- $\quad$ Grouting \& Repair of cracks

- $\quad$ Repair of decayed doors \& windows

- $\quad$ Lime plastering of external \& internal wall surfaces.

- Decorative plastering on columns, cornices and wall heads.

- Lime wash of the building structure

- Addition of a water proofing layer at the terrace level to stop seepage of water through the terrace.

- Opening of all the drains and drainage outlets.

\section{PRELIMINARY SOLUTIONS REPORT}
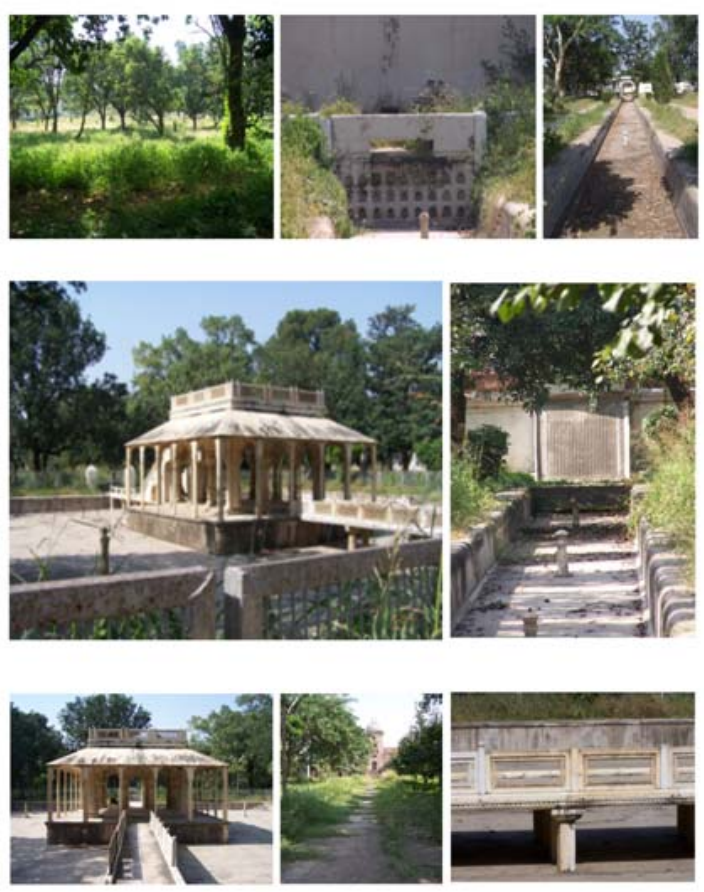

IMAGE BOARD SHOWING THE EXISTING CONDITIN OF THE 'CHAR BAGH' GARDEN

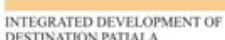
INTEGRATED DEVELOPM
DESTINAIION PALALA

PATLALA

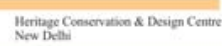

Figure 13: The Char Bagh
Items of landscape work

Conservation interventions in the chahar bagh are aimed at enhancing the integrity and spatial character of the historic chahar bagh. This would imply removal of wild vegetation, restoration of the baradari in the centre, the fountains along the axis, the water tank on the terrace, the chaddar (water sheet) feeding the water channels.

Through planting that would have been a part of the chahar bagh the modern structures abutting the chahar bagh would be screened off.

Various pause points that would have been part of the chahar bagh experience would be retrieved so that the visitors experience the garden in the same manner as the royalty would have in the nineteenth century

Through excavations the original levels of the planting beds will be exposed. Vehicular traffic within the chahar bagh is to be stopped. The potential of restoring water in the fountains and channels of the chahar bagh will be explored.

Planting both in terms of species and planting systems that are in keeping with the historic chahar bagh character will be proposed. All existing trees will be retained. An inventory of all existing trees recording them as heritage features will be made.

Signage explaining the significance of the site will be sited at the entrance and at various points within the garden.

\section{CONCLUSIONS}

This exercise mainly focuses on the application of existing and emerging surveying techniques applied for condition mapping of deteriorated surfaces in historic buildings. The use of nondestructive analytical tools has been impressed upon as a complementary method to produce images that provide information regarding the interior and exterior surfaces.

The documentation process achieved the primary aim of producing heritage mapping and inventories for the historic structure and garden components of the complex, representative of the city's cultural heritage. It also created a digital database consisting of physical qualitative attributes data for future management and recording for posterity. The challenges faced while attempting the exercise were mainly due to financial and time constraint however data base collection should be designed with possibilities of serving long term goals in cultural resource management.

\section{ACKNOWLEDGEMENTS}

The work presented here was undertaken by the team of Heritage Conservation \& Design Centre, New Delhi, India. as part of the Punjab Tourism project ' Integrated Development of Destination Patiala' for the Govt. of Punjab, India. The Author would like to thank all officials of the Punjab Government (Punjab Heritage Tourism Promotion Board) for their help and valuable inputs whenever required. 


\section{REFERENCES}

1. R. S. Letellier, W. LeBlanc, F. Guiding Principles recording, documentation, and Information Management for the Conservation of Heritage Places. Los Angeles, USA: Getty Conservation Institute, 2007.

2. UNESCO, 16 November 1972. Convention Concerning the Protection of the World Cultural and Natural Heritage

3. UNESCO, 2013. Operational Guidelines for the Implementation of World Heritage Convention.

4. Gupta, Divay, INTACH (UK) Trust, 2007. Conservation Briefs , identification and Documentation of Built Heritage in India

5. D. Watt, Surveying Historic Buildings : Donhead, 2010.

6. J. McCarthy, "Multi-image photogrammetry as a practical tool for cultural heritage survey and community engagement," Journal of Archaeological Science, vol. 43, 2014. 